\title{
Objective evaluation of vibration comfort through the design of a vibration filter - Implementation of a study design for vibration comfort evaluation
}

\author{
Diana Fotler ${ }^{1}$, Tassilo Schröder ${ }^{1}$, René Germann ${ }^{1}$, Sven Matthiesen ${ }^{1 *}$ \\ ${ }^{1}$ IPEK - Institute of Product Engineering at Karlsruhe Institute of Technology (KIT) \\ * Corresponding author: \\ Sven Matthiesen \\ Kaiserstraße 10 \\ 76131 Karlsruhe, Germany \\ Telefon: +49 721/608 47156 \\ Mail: sven.matthiesen@kit.edu
}

\begin{abstract}
In order to design products that are optimised for the user, it is important to take the user's perception of the product into account as early as possible, whereby this is strongly influenced by the vibrations that occur. For the use of power tools, there is currently a lack of knowledge about possible influencing factors and the resulting perception of the user. Within this manuscript, a study design is presented with which potential influences on vibration perception can be investigated. The implementation of study design is based on the most important influencing factors within the perception and judgement process of vibration comfort, which originate from an expert workshop and a literature research in the field of psychology.
\end{abstract}

\section{Keywords}

User Studies, Influencing Factors, Perception and Judgement Formation of Stimuli, Human-Machine Systems 


\section{Introduction}

In user-centered design, productivity and ergonomics are central parameters for achieving an increase in the value of products and thus being marketable. Productivity is proved dependent on the perceived comfort of the user during application [1, 2]. Vibration emissions, which affect the user, represent a particularly intensively perceived comfort aspect. Vibration emissions stress the user both physically and psychologically. Therefore, vibration exposure of the human body due to human-machine interaction is an extensively studied topic in the current state of research [3-8].

In the field of power tools, the state of research focuses primarily on the physiological effects on the human hand-arm system caused by vibration exposure from power tools [6, 9-11]. With regrad to the product development of power tools the research results were translated into industry standrads and metrics such as the $a_{\text {hv }}$ value, which is defined in the industry standard DIN EN ISO 5349-1 [12].

At the current state of research on power tools, the $a_{\text {hv }}$ value only covers the physiological effects of vibration exposure and does not consider the psychological impact of vibration emission. Since there is already extensive research on the relationship between vibration and comfort in the automotive sector, it can be assumed that the perceived comfort of power tools is also influenced by the psychological effect of vibration exposure [5, 13-16]. Nevertheless, the knowledge gained between vibration emission and comfort from the automotive sector cannot be transferred to power tools, as the frequency range of the emitted vibrations differs greatly. In addition, studies show that the $a_{\text {hv }}$ filter of vibration does not coincide with the comfort ratings and is thus not suitable for the comfort ratings due to vibration $[17,18]$.

In consequence the psychological effects of vibrations emitted by power tools on operator comfort can neither be derived from the current state of research nor quantified by the established metrics in the field of power tool vibration emission.

Regarding the realtion between the vibration emission of power tools and the cognitive percepted comfort, different influence factors on the human perception have to be considered. In the field of hand-arm vibration, the vibrations transmitted from the power tool to the handarm system depend on the gripping and pressing force [12, 19-21]. Therefore, it is reasinable to assume that these factors have to be considered in the perceived comfort as well.

Furthermore, the state of biology and psychology on human perception of vibrations shows that humans perceive frequencies especially in the range of $10 \mathrm{~Hz}$ to $300 \mathrm{~Hz}$ with particular intensity. Moreover, this perception can be overlaid by other stimuli, such as optical or acoustic impressions, or interact with influencing factors. Therefore, when investigating vibration comfort, it is important to represent the overall environment as realistic as possible. Furthermore, as previous studies have demonstrated, comfort and fatigue during use of a handheld device varies for each individual [17]. The manuscript addresses a lack in research of finding an appropriate way to deal with these difficulties. Herein the manuscript identifies the factors that influence vibration comfort as well as the related measurands and offering suggestions on how to deal with them. In order to analyze the comfort related to the vibration emission of power tools the different influencing factors have to be defined and evaluated in studies due to their expected dominance an the percepted comfort within the power tool usage. Hence the manuscript is adresses the following research questions:

Research Question 1: Which influencing factors must be considered when investigating the vibration comfort of power tools?

Research Question 2: What does the perception and judgement process of vibration comfort look like and which influencing factors are involved here? 
Research Question 3: What should a study design look like in order to investigate relevant influencing factors on the perception and judgement process of vibration comfort?

\section{Methods}

To identify relevant user influences on vibration and vibration comfort and to answer the research question, a workshop was held with 15 participants. These participants are employees in leading positions in development teams from industry who regularly carry out studies to record vibration of power-tools.

They were asked to answer the following question via brainstorming: What variables affect the vibration comfort of power-tools using the example of angle grinders and hammer drills? There were 20 minutes available for free collecting. Afterwards, the mentioned variables were combined on a common board and sorted according to the topics Human Factors, Environmental Factors and Product Properties. Doubly named variables were piled on top of each other. In the next step, the collected variables were evaluated which variables should be considered in an experiment to measure vibration comfort of power-tools by subjects. The evaluation should be made on a scale of 0 (very unimportant to consider) to 10 (very important to consider). In the third and final step, subjects were asked which variables should be varied and which should be kept constant in such an experiment.

The results of the questioned subjects were summarized in a table that presents (potential) influencing factors on the measurement of vibration comfort.

Following the workshop, the influencing factors originating from humans, which were rated as extremely important (at least rated as 7), were analyzed in more detail on the basis of a literature research.

In addition, with the help of a literature search, it was analyzed how stimuli are created, perceived and evaluated in psychology. Processes for understanding and variables influencing this process were investigated. On the basis of this research, a process picture was created, which shows the process up to a general evaluation by humans and in which the influencing variables from the literature are shown. From this process picture and the influencing factors that were named in the workshop, a table of human influencing factors on the measurement of vibration comfort was created. The table also provides the justification for why these variables need to be considered and how they should be dealt with in a study. These as relevant defined influencing factors were transferred to a study design. The study design is intended to assist in studies on subjectively perceived evaluations, to pay attention to influencing factors in a targeted manner and to query their influence.

Furthermore, the human factors defined as important from the expert workshop were combined with the identified influencing factors from the literature on the perception and evaluation of stimuli. Very similar, probably highly correlated, influencing factors were combined into one, which appeared to have a more direct influence on vibration comfort. Subsequently, these combined influencing factors were evaluated in terms of relevance and implementability. Influencing factors with an obviously low relevance or a low possibility to be considered in a study were sorted out. All remaining influencing factors were finally integrated into a study concept for the assessment of vibration comfort.

\section{Results}

\section{Influencing factors on vibration comfort}

First, possible user influences were collected in the workshop. These are sorted according to the topics Human Factors, Environmental Factors and Product Properties as shown in Table 1. All influencing factors that, on average across all total ratings, were rated at least as seven 
on the ten-point scale are shown in bold. In the brackets below is the rating of the participants (by absolute majority) of all evaluating influencing factors, whether these should be kept constant or varied within a study ( $c=$ keep constant, $v=$ variate).

Table 1: Influencing Factors on Vibration Comfort

\begin{tabular}{|c|c|c|}
\hline Human Factors & Environmental Factors & Product Properties \\
\hline Position hand (c) & Temperature (c) & Output power (c) \\
\hline $\begin{array}{l}\text { Direction of use per } \\
\text { application (c) }\end{array}$ & $\begin{array}{l}\text { Noise }(\mathrm{c}) \\
\text { Fixation workpiece }\end{array}$ & $\begin{array}{l}\text { Performance total } \\
\text { system }\end{array}$ \\
\hline $\begin{array}{l}\text { Arm position (c) } \\
\text { Posture (c) }\end{array}$ & Material (c) & $\begin{array}{l}\text { With / without speed } \\
\text { control }\end{array}$ \\
\hline $\begin{array}{l}\text { Posture (C) } \\
\text { Ethnicities }\end{array}$ & $\begin{array}{l}\text { Floor space (material) } \\
\text { Additional vibrations of }\end{array}$ & Handle shape (v) \\
\hline Experience (expert / & $\begin{array}{l}\text { Adher machines } \\
\text { othe of }\end{array}$ & Handle feel \\
\hline $\begin{array}{l}\text { layman) (v) } \\
\text { Individual sensation }\end{array}$ & $\begin{array}{l}\text { Measuring method } \\
\text { (standard measurements!) }\end{array}$ & $\begin{array}{l}\text { Surface texture, material } \\
\text { Housing material }\end{array}$ \\
\hline of vibration & With / without gloves & Tilter / decoupling systems \\
\hline $\begin{array}{l}\text { Tiredness } \\
\text { Attention } \\
\text { Clothing }\end{array}$ & $\begin{array}{l}\text { Feedback of application / } \\
\text { workpiece }\end{array}$ & $\begin{array}{l}\text { Weight }(\mathrm{v}) \\
\text { Spectrum of vibrations } \\
\text { at the handle }(\mathrm{v})\end{array}$ \\
\hline $\begin{array}{l}\text { Subjective } \\
\text { interactions }\end{array}$ & & $\begin{array}{l}\text { Vibration behavior } \\
\text { Mass }\end{array}$ \\
\hline Expectations & & Unbalance (mass) \\
\hline $\begin{array}{l}\text { Hand size and } \\
\text { weight }\end{array}$ & & $\begin{array}{l}\text { Surface properties } \\
\text { Tool }\end{array}$ \\
\hline Hand-arm system & & $\begin{array}{l}\text { Power Tool / workpiece } \\
\text { interaction }\end{array}$ \\
\hline $\begin{array}{l}\text { Distribution of hand } \\
\text { force over two grips }\end{array}$ & & $\begin{array}{l}\text { Power Tool / device } \\
\text { interaction }\end{array}$ \\
\hline \multicolumn{3}{|l|}{ Grip force (v) } \\
\hline \multicolumn{3}{|l|}{ Operating forces (v) } \\
\hline Pressing force (v) & & \\
\hline
\end{tabular}

\section{Perception and judgement process of vibration comfort}

In order to obtain a holistic picture of potential human influencing factors within the investigation of vibration comfort of power tools, psychology is used as an auxiliary science. It is considered in the literature how external stimuli are perceived and how a subjective evaluation of a stimulus is formed. In addition, influencing factors are identified which have an impact on the perception and judgement process of stimuli as well as where they occur within this process. The result of the research is presented as a process picture in Figure 1. 


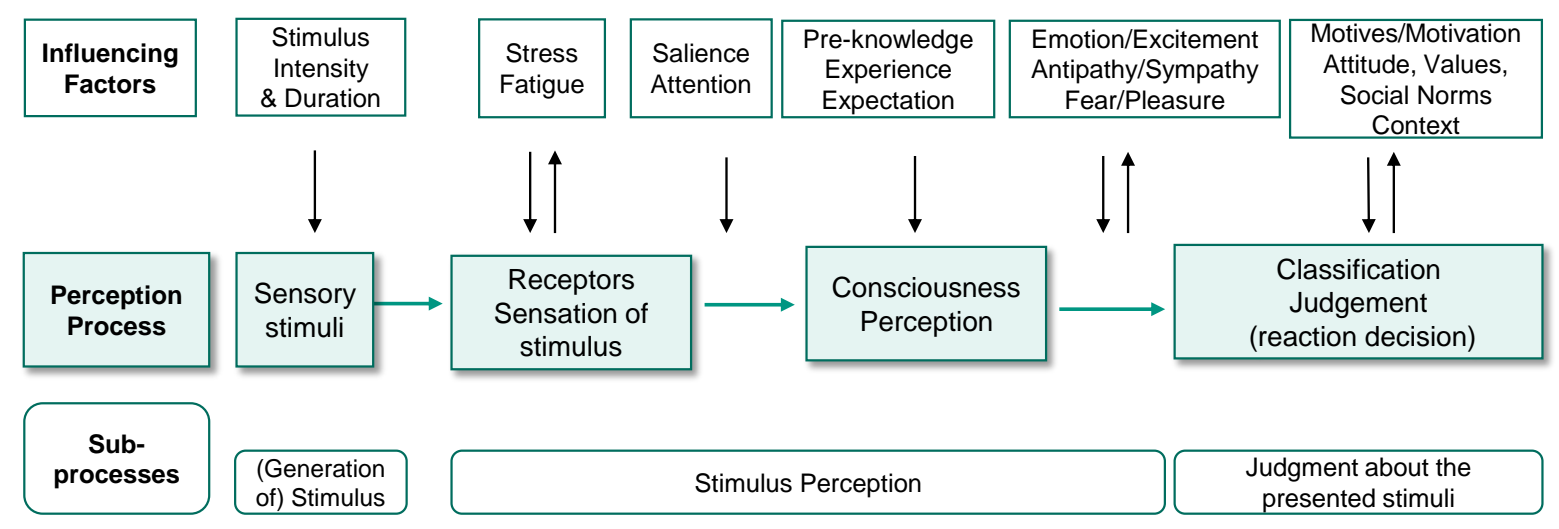

Figure 1: Perception and Judgement Process [22-24]

The investigation of vibration comfort can be divided into a total of three sub-processes that are influenced by humans: stimulus generation, stimulus perception and the formation of judgements about the stimulus presented. Figure 1Figure 1 shows these sub-processes below. The influencing factors that significantly determine the corresponding sub-processes are listed above. The process steps of stimulus perception and judgement formation are based on cognition. Cognition is a collective term for processes and structures that affect the reception, processing and storage of information [22]. In psychology, cognition is a well-researched process in which there is a high level of awareness of many individual human influencing factors [23]. Raab (2016) describes the following elements as the most important cognitive systems: presumed knowledge / hypotheses, attitudes and social norms [23]. Hypotheses are understood here to imply that every person makes assumptions that filter what is perceived and evaluated in what way. Attitudes are understood as expectations in perception [23, 25]. This includes above all values and prejudices that influence the process of judgement. Moreover, according to the directive state concept of Bruner and Postman 1951, people's perception is influenced by their needs, motives, values and desires [23]. There is no such unbiased perception [23]. This can be observed well in the example of the brand of a product: The perception of the brand leads to a hypothesis, which subsequently influences the perception of properties [23, 26].

An important perceptual filter is salience, which contributes to attention. Salience describes the difference and noticeability of a stimulus in relation to the context [24, 27]. This makes the stimulus more accessible to the consciousness [24]. Causes for this can be the relevance of the stimulus for the person's current objectives or the contradiction of expectations [24, 28].

Stimulus intensity and spectral contrast play a decisive role in the salience filtering of sound [24]. It is therefore assumed that a transferability of these conditions to vibration can be carried out.

In summary, it can be stated that the evaluation of the vibration comfort goes through the sub-processes of stimulus generation, stimulus perception and judgement formation of the presented stimulus. The human influencing variables determine each sub-process individually.

An example: The greater the perceived stress of a person, the more limited the possibility of perceiving sensory stimuli via various receptors and the stronger the filtering of sensory stimuli takes place. Two people with different levels of perceived stress in the same application notice the stimuli differently and consequently evaluate them differently. This selection of perception is guided by attention [24] and influenced by various dispositions such as the interest or goals of the person [23, 29]. 


\section{Study design to investigate relevant influencing factors on vibration comfort}

In order to be able to investigate influencing factors on vibration comfort as validly, objectively and reliably as possible across different subjects, despite the individuality, a consideration of a suitable study design for the human influencing factors must take place.

The study concept for the assessment of vibration comfort is illustrated in Figure 2. It contains the combined, evaluated and selected influencing factors from the expert workshops and the perception and judgement process. The basic requirement for the study design to work is that all other potential influencing factors are kept constant. For example, each subject receives the same protective clothing, the same standardized specifications for performing applications, the same test environment with the same test instructors.
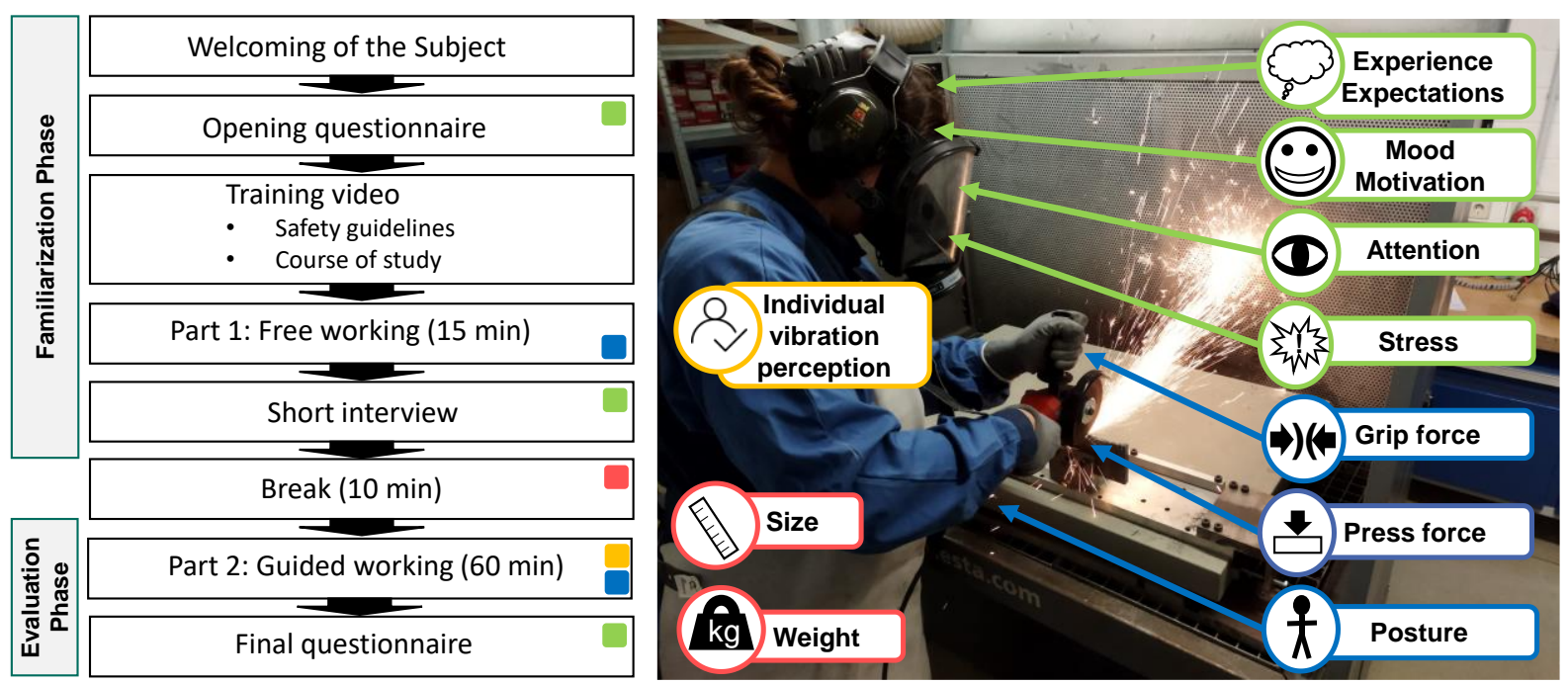

Figure 2: Study Design for Measuring Influencing Factors on Vibration Comfort

In Figure 2, a proposal for a study procedure is presented on the left side. The study consists of two main phases: the familiarization phase and the evaluation phase. The familiarization phase is concerned with getting subjects used to all environmental stimuli in the form of the experimental environment, the instructor, the task, the power tools, the questions and the observation. All stimuli presented up to this point should be perceived as non-salient and the subjects should be given the opportunity to work as realistically as possible in Part 1 and to find a comfortable posture, gripping and pressing forces. In Part 1, no adjustment of influencing factors takes place, only a recording takes place.

In the evaluation phase, measurements are taken at the beginning to determine the individual vibration sensation. As these are often difficult to implement, reference measurements can be taken instead at the beginning and end to anchor the reference system (psycho source). In guided working, the applications with the power tools are precisely defined and also randomized. The applications are evaluated one after the other with regard to the perceived vibration intensity and vibration comfort on a five-point Likert scale, for example. In addition, the subjects are asked to indicate whether they rated the applications on a five-point Likert scale as very easy to very difficult and whether they noticed anything special about the application. There is a break between the two phases to prevent premature fatigue and to ensure that subjects are not overly biased in their assessment of vibration comfort as a result of the familiarization phase. In order to distract the subjects, their height and hand size, their weight and, at best, other demographic and anthropometric data are measured during the break. The influencing factors shown in green are repeatedly asked about or measured during 
the entire course of the study in order to be able to evaluate the vibration comfort of the subjects.

\section{Discussion}

In the first step within an expert workshop, factors were collected that have an influence on vibration comfort, using angle grinders and hammer drills as examples. These were sorted into the topics Human Factors, Environmental Factors and Product Properties. Subsequently, a weighting was carried out according to relevance in measurements and an assessment of how to deal with the influencing factors during an investigation.

This assessment, carried out by experts in product development in the field of power tools, is extremely useful. It provides information on where the focus has been so far in conventional vibration measurements and in studies with subjects, which influencing factors are already known and which are suspected.

This collection and evaluation of factors that have an influence on the vibration comfort of power tools must be considered in studies is based on subjective experience.

In the second step, a literature research was carried out to look at the perception and judgement process of vibration comfort and to analyze the corresponding influencing factors. The process of stimulus generation, perception and evaluation is extremely meaningful. Through the differentiated consideration of influencing factors on a subjectively evaluated variable within the process steps, the influences with their interactions can be better understood and thus more easily considered. Measured correlations or effects of an investigation can be traced back to their potential causes using the process. The structured procedure also enables the reduction of factors with a high degree of probability. The large number of factors and the great individual differences of subjects in their characteristics render a holistic recording very difficult and, above all, time-consuming. A priority and combination, a so-called index formation, of the influencing factors is therefore highly recommended.

In the third step, the influencing factors from the expert workshop that were rated as important were combined, evaluated and selected with the influencing factors in the perception and assessment process. The most important influencing variables were transferred into a study design. The study design supports the investigation of relevant influencing factors on the perception and judgement process of vibration comfort.

The structured procedure and the specific consideration of the influencing factors in the study design reduces the influence of the factors as well as their number with high probability. For other subjectively perceived and evaluated variables in the area of power tools, a transferability of the study design is possible. Depending on the power tool, task and size, adjustments are probably necessary.

Limitations: The current study design lacks consideration of how precisely the specified influencing factors can be measured. It is certainly possible and sensible to use a wider range of measurement methods than questionnaires. Further research and adjustments are needed here. These may be added to the study design in future studies as needed.

\section{Conclusion}

In order to design products that are optimized for the user, it is important to take the user's perception of the product into account as early as possible, whereby this is strongly influenced by the vibrations that occur, among other things. For the use of power tools, there is currently a lack of knowledge about possible influencing factors and the resulting perception of the user. 
Within this manuscript, a study design is presented with which potential influences on vibration perception can be investigated.

An expert workshop was held to find out the influencing factors on vibration comfort. In addition, a literature research was conducted in the field of psychology on stimulus generation, perception and evaluation in order to identify relevant factors influencing the evaluation of vibration and to be able to justify their use in a study. Finally, the most relevant influencing factors from the expert workshop and the literature research were combined, evaluated and selected. Subsequently, these were transferred into a study design, which investigates relevant influencing factors on the perception and judgement process of vibration comfort. The experiences from everyday vibration measurements could thus be combined with the broad knowledge of psychology within the perception and judgement of stimuli. The study design can be transferred and used for other subjectively perceived and evaluated stimuli and provides an overview of relevant factors that influence the perceived comfort of vibration in power tool applications.

\section{References}

[1] Dianat, Iman ; Nedael, Moein ; Mostashar Nezami, Mohammad Ali: The effects of tool handle shape on hand performance, usability and discomfort using masons' trowels. In: International Journal of Industrial Ergonomics 45 (2015), S. 13-20

[2] KUIJT-Evers, L.F.M. ; VINK, P. ; LOOZE, M. P. de: Comfort predictors for different kinds of hand tools : Differences and similarities. In: International Journal of Industrial Ergonomics 37 (2007), Nr. 1, S. 73-84

[3] AlBers, Albert ; SCHILle, Fabian ; BEHRENDT, Matthias: Maneuver-Based NVH Investigations of the Internal Combustion Engine Starting Behaviour in Hybrid Vehicles : ATZlive - Automotive Acoustics Conference 2015. In: 3rd International ATZ Conference. Wiesbaden : Springer Fachmedien Wiesbaden GmbH, 2015

[4] VDI-Richtlinie 2057 Blatt 2. März 2016. Einwirkung mechanischer Schwingungen auf den Menschen

[5] Frankhauser, Christoph ; Riepl, Anton; Wolauschegg, Stefan: Simulation of Vibrational Driving Comfort Criteria. In: MAGNA STEYR (Hrsg.): Conference 'Computer Simulation in Automotive Engineering', 2001

[6] LAGE BURSTRÖM: The influence of biodynamic factors on impedance. In: International Arch Occup Environ Health 1997 (1997), Nr. 69, S. 437-446

[7] DIN EN ISO 20643. Oktober 2012. Mechanische Schwingungen - Handgehaltene und handgeführte Maschinen

[8] SCHENK, Thomas: Schwingungsmessung - Personengebundene Messung am Arbeitsplatz : Messeinrichtung zur personengebundenen Messung von Hand-Arm- und Ganzkörperschwingungen am Arbeitsplatz. Dortmund, 2002 (Arbeitswissenschaftliche Erkenntnisse 130)

[9] Dong, Ren G. ; Welcome, Daniel E. ; Wu, John Z. ; McDoweLL, Thomas W.: Development of hand-arm system models for vibrating tool analysis and test rig construction. In: Noise Control Engineering Journal 56 (2008), Nr. 1, S. 35-44

[10] KAULBARS, U.: Schwingungen fest im Griff. In: Technische Überwachung-Düsseldorf 47 (2006), Nr. 6, S. 35

[11] DIN 45679. Februar 2013. Mechanische Schwingungen - Messung und Bewertung der Ankopplungskräfte zur Beurteilung der Schwingungsbelastung des Hand-Arm-Systems

[12] EN ISO 5349-1. Dezember 2001. Mechanische Schwingungen - Messung und Bewertung der Einwirkung von Schwingungen auf das Hand-Arm-System des Menschen

[13] APL-2015: 2019_Laroche_relationship between hand-arm vibration and subjective evaluation by a magnitude estimation method. In:

[14] Bellmann, Michael A.: Perception of Whole-Body Vibrations: From basic experiments to effect of seat and steering-wheel vibrations on the passengers comfort inside vehicles. Oldenburg, Universität Oldenburg. Dissertation. 1972

[15] Deprez, Koen ; Moshou, Dimitrios ; Anthonis, Jan ; Baerdemaeker, Josse de ; Ramon, Herman: Improvement of vibrational comfort on agricultural vehicles by passive and semi-active cabin suspensions. In: Computers and Electronics in Agriculture 49 (2005), Nr. 3, S. 431-440

[16] NISHIYAMA, S. ; UESUGI, N. ; TAKESHIMA, T. ; KANO, Y. ; TOGII, H.: Research on Vibration Characteristics between Human Body and Seat, Steering Wheel and Peadals (Effect of Seat Positon on Ride Comfort). In: Journal of Sound and Vibration 236 (2000), S. 1-21

[17] PIES, Daniel: Reifenungleichförmigkeitserregter Schwingungskomfort - Quantifizierung und Bewertung komfortrelevanter Fahrzeugschwingungen. Karlsruhe : KIT Scientific Publishing, 2012 (Karlsruher Schriftenreihe Fahrzeugsystemtechnik 12) 
[18] Zimprich, Sebastian; Germann, René; Helmstetter, Sebastian; Saurbier, Simon; Matthiesen, Sven: An Objective Rating Approach for Vibration Discomfort Evaluation in Power Tool Ergonomics - Examination of Higher Frequency Components, Bd. 1253. In: AHRAM, Tareq; TAIAR, Redha; LANGLOIS, Karine; CHOPLIN, Arnaud (Hrsg.): Human Interaction, Emerging Technologies and Future Applications III. Cham : Springer International Publishing, 2021 (Advances in Intelligent Systems and Computing), S. 84-90

[19] Dong, R. G.; Rakheja, S.; Schopper, A. W.; Han, B. ; Smutz, W. P.: Hand-transmitted vibration and biodynamic response of the human hand-arm: A critical review. In: Critical Reviews in Biomedical Engineering 29 (2001), Nr. 4, S. 393-439

[20] KaUlBars, U.; LeMERLE, P.: Messung der Ankopplungskräfte zur Beurteilung der Hand-Arm-SchwingungenWeiterentwicklung eines Messsystems. In: VDI-Berichte 2002 (2007), S. 99-111

[21] Lindenmann, Andreas; MatTHIESEN, Sven: The Rotational Mechanical Impedance of the Hand-Arm System : A Preliminary Study. In: Institut für Arbeitsschutz der Deutschen Gesetzlichen Unfallversicherung (IFA) (Hrsg.): 14th International Conference on Hand Arm Vibration : -Abstracts-. Berlin : Deutsche Gesetzliche Unfallversicherung (DGUV), 2019 (14), S. 75-76

[22] HÄNSEL, Frank; BAUMGÄRTNER, Sören D.; KoRNMANN, Julia; ENNIGKEIT, Fabienne: Sportpsychologie. Berlin, Heidelberg: Springer, 2016 (Springer-Lehrbuch)

[23] RAAB, Gerhard; UnGER, Alexander; UNGER, Fritz: Marktpsychologie: Grundlagen und Anwendung. 4., vollständig überarbeitete Auflage. Wiesbaden: Springer Gabler, 2016

[24] STEFFENS, Jochen: How much reality do humans need?: Investigations into the influence of the test Environment on the noise assessment of household appliances. Berlin, TU Berlin, Faculty V-Traffic and Machine Systems. Dissertation. 2013. URL https://depositonce.tuberlin.de/bitstream/11303/4029/1/steffens_jochen.pdf - Überprüfungsdatum 2021

[25] JANEKSELA, GALAN M.: PREDICTING BEHAVIOR FROM ATTITUDES: PROBLEMS AND SOLUTIONS. In: International Review of Modern Sociology 8 (1978), Nr. 2, S. 245-256. URL http://www.jstor.org/stable/41420659

[26] Germann, René; KuRTh, Lukas; Matthiesen, Sven: Disruptive factors in the evaluation of perceived quality aspects - consideration of the brand influence. In: International Journal of Industrial Ergonomics 76 (2020), S. 102931

[27] Betsch, Tilmann; FunKE, Joachim; PlessneR, Henning: Denken - Urteilen, Entscheiden, Problemlösen: Mit 14 Tabellen. Berlin: Springer, 2011 (Springer-Lehrbuch Allgemeine Psychologie für Bachelor)

[28] GerRIG, Richard J.; ZIMBARDo, Philip G.: Psychologie. 21., aktualisierte und erweiterte Auflage. Roos, Jeanette (Hrsg.); DöRfLER, Tobias (Hrsg.). Hallbergmoos: Pearson, 2018

[29] HagendorF, Herbert; KrummenacheR, Joseph; MülleR, Hermann-Josef; Schubert, Torsten: Wahrnehmung und Aufmerksamkeit: Allgemeine Psychologie für Bachelor. Berlin, Heidelberg: Springer-Verlag Berlin Heidelberg, 2011 (Springer-Lehrbuch) 